\title{
Life-Cycle Assessment on Nickel-Metal Hydride Battery in Hybrid Vehicles: Comparison between Regenerated and New Battery
}

\author{
SHUOYAO WANG \\ JEONGSOO YU \\ GRADUATE SCHOOL OF INTERNATIONAL CULTURAL STUDIES, TOHOKU UNIVERSITY, \\ 41 KAWAUCHI, AOBA-KU, SENDAI-ShI, MiYaGi PREFECTURE 980-8576, JAPAN \\ wang.shuoyao.q7@dc.tohoku.ac.jp \\ jeongsoo.yu.d7@tohoku.ac.jp
}

\begin{abstract}
To reduce air pollution and avoid petroleum exhaustion problem, many advanced countries, especially Japan installed Hybrid Vehicles (HV). As the use of HV popularizes around the world, there will be a huge amount of End-of-Life HV in the near future, and the proper treatment of these End-of-Life HVs, especially the waste NiMH (Nickel-Metal Hydride) batteries, will become a serious problem. Currently, the recycling of NiMH battery is gaining substantial attention. However, instead of recycling waste $\mathrm{NiMH}$ batteries directly, regenerating and reusing a used NiMH battery for a secondhand $\mathrm{HV}$ will largely reduce waste battery generation and demand for new NiMH battery. However, the environmental impact of regenerating and reusing a waste NiMH battery was not clear and has not been compared with the situation when using a brand-new NiMH battery. The purpose of this research is to compare the environmental performance ( $\mathrm{CO}_{2}$ emission) of regenerated $\mathrm{NiMH}$ battery and brand-new $\mathrm{NiMH}$ battery in an HV from their production to usage stage and to discuss the validity of using a regenerated $\mathrm{NiMH}$ in Japan and in other countries using the Life-Cycle Assessment (LCA) approach. This research analyzed the composition of a NiMH battery and the $\mathrm{CO} 2$ emission during the manufacture, transportation, regeneration and usage process of a NiMH battery. The data used in this research was collected from reports and data published by the government of Japan, vehicle makers and previous studies. Original field survey and interview research on battery regeneration operators were also performed. The result showed that there is not a big difference in
\end{abstract}


environmental effect. Moreover, by doing so, a huge amount of resource will be saved from battery manufacturing process while reducing waste generation. It is recommended that waste NiMH battery should be regenerated and reused in $\mathrm{HV}$ instead of being recycled directly in the future.

Keywords: Nickel-Metal Hydride Battery, Hybrid Vehicle, Reuse and Recycling, Life Cycle Assessment, Efficient use of Resources

\section{Introduction}

To solve petroleum exhaustion and air pollution problem, Hybrid Vehicles (HV), which refers to vehicles consisting of both engine and driving battery, are gaining popularity in many advanced countries. Concretely, the sale of HV around the world increased by about four times in a 5-year period (2017 data). Japan occupies about 70\% of global HV sale, which makes it the biggest $\mathrm{HV}$ market in the world. On the other hand, the Nickel-Metal Hydride (NiMH) batteries in HV will emerge as used batteries soon. Therefore, the proper treatment of these NiMH batteries is getting much attention. In fact, there will be around 20,000 used NiMH batteries in Japan waiting to be recycled properly (Ministry of Economy, Trade and Industry of Japan 2015). Ortego et al. (2018) evaluated the value of nickel, cobalt, and lithium in the vehicle and the significance to recycle these materials from the point of view of Thermodynamic. Ebin et al. (2018) focused on AA- and AAA-type of NiMH battery and pointed the need to ameliorate waste battery pretreatment before the recycling process. HV battery recycling technology to improve the recycling rate for nickel, cobalt and related rare earth has also been discussed ( $\mathrm{Hu}$ et al. 2013; Korkmaz et al. 2018). Recycling method which could improve the rare earth elements' recycling rate while reducing environmental burden has been brought up (Yao et al. 2018). However, these articles are mainly discussing recycling technologies instead of battery reuse technologies. On the other hand, the environmental effect and the possibility to replace the lead-acid battery with regenerated LIB battery from electric vehicles in a stationary energy storage system have been analyzed (Richa et al. 2017). According to the result, by extending the life of LIB battery, the environmental burden generated during battery manufacture process can be shared with the stationary energy storage system. However, only LIB was studied and the environment effect of regenerating and reusing the waste battery into a vehicle again has not been considered. Actually, if waste NiMH battery can be regenerated and reused in HV, the amount of waste NiMH battery will be largely reduced, and the demand for repairing batteries will also be satisfied. However, the environmental impact of doing so is still unclear. 
Shuoyao Wang, Jeongsoo Yu: Life-Cycle Assessment on Nickel-Metal Hydride Battery in Hybrid Vehicles: Comparison between Regenerated and New Battery

In this research, the environmental impact of making and using a newly-repaired NiMH and a regenerated repaired battery will be compared using Life-Cycle Assessment (LCA) measure. The impact of resource-saving as well as waste reduction effect will also be analyzed. Based on the result, the proper reuse and recycling policy for waste $\mathrm{NiMH}$ batteries in the future will be proposed. In this research, "repaired battery" refers to batteries which will be used in an HV when the original battery is broken. The repaired battery could be a secondhand battery. In the next section, basic information (such as the material and weight, etc.,) about NiMH in HV will be introduced.

\section{Basic Information of NiMH}

There are mainly two kinds of NiMH battery for $\mathrm{HV}$, the circle shape and square shape NiMH battery. The most common type is square-shaped $\mathrm{NiMH}$ battery nowadays. Therefore, the research object in this thesis will be a square-shaped NiMH battery used in the Prius (3rd generation). The weight of a NiMH battery is around $39.07 \mathrm{~kg}$ and consists a battery case and 28 battery modules. Each module weighs $1.04 \mathrm{~kg}$. The voltage is $201.6 \mathrm{~V}$ and the capacity is $6.5 \mathrm{Ah}$, the power capacity is estimated to be 1,310 Wh.

When comparing the environmental impact of multiple products using LCA method, research objects should be unified into the same functional unit. Therefore, in this research, the function of a NiMH battery is defined as "to assist vehicles' engine and improve vehicles' fuel consumption" and the functional unit is "one repaired battery in HV". The life span of a $\mathrm{NiMH}$ battery is estimated to be five years which is the same as the battery warranty period.

\section{LCA Scope for NiMH Battery}

LCA scope covers the environmental impact of each process from production to shipment and associated with $\mathrm{CO} 2$ emission. The method for unification is by multiplying the resources and energy used during each process by their $\mathrm{CO} 2$ emission intensities. The recycling method for repairing battery (both new and regenerated one) is considered to be the same so the $\mathrm{CO}_{2}$ emission should have no diversity, hence, the final recycling process is not included in this research. Therefore, only the process in full line is in the research scope and the process in short dashes line is not analyzed. Moreover, the environmental impact during the usage process will be mentioned afterwards.

\section{1 LCA Scope for New NiMH Battery}

As shown in Fig.1, the research scope for the newly repaired battery includes the manufacture of raw material for battery, the shipment of raw material, the production and assembly of each component and the batteries' shipment process. 


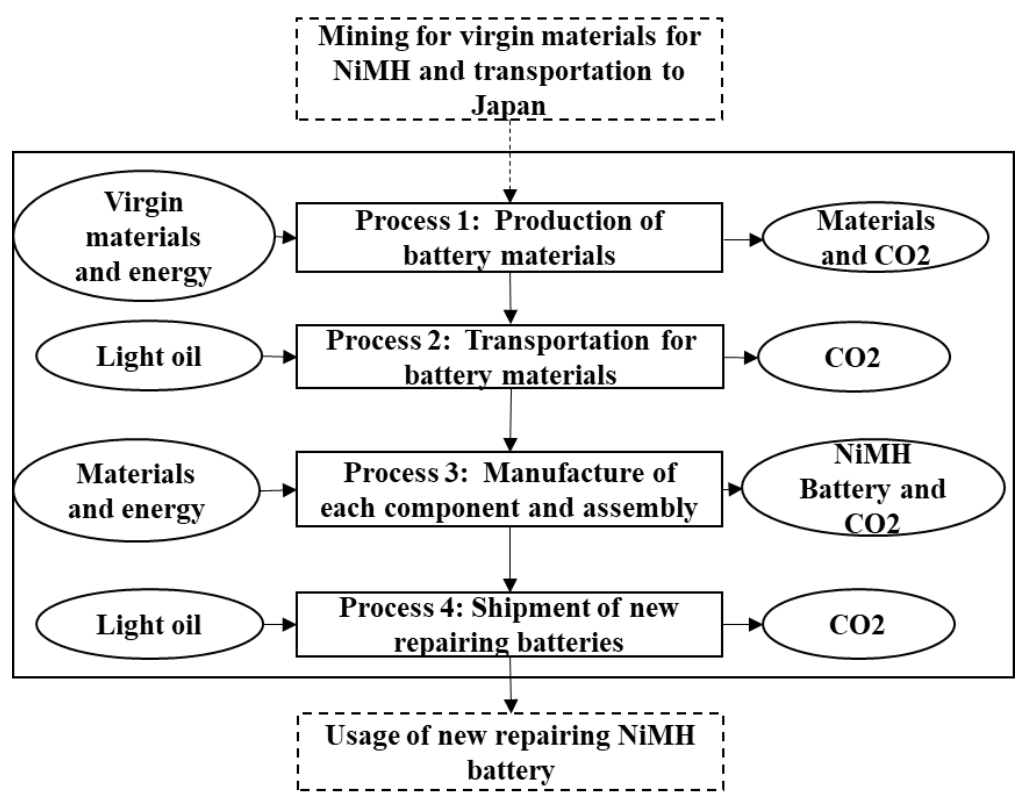

Fig. 1: Research Scope of new repairing NiMH batteries for $H V$ Figure 1 was created by the author

To make a new repairing NiMH battery, necessary materials should be refined first. In this research, all the waste NiMH batteries were considered to be recycled and stored within Japan and, therefore, overseas mining and transportation are not considered. These materials are transported to a battery manufacturing plant and disassembled into battery components. After that, each component will be assembled into new repairing NiMH batteries and shipped out.

\section{2 LCA Scope for Regenerated NiMH Battery}

The scope for the regenerated repairing $\mathrm{NiMH}$ batteries includes collection, performance test, regeneration and shipment process. After waste NiMH batteries were collected from dismantlers and transported to a regeneration plant, battery regeneration manufacturer will dismantle the NiMH battery to module-level by hand. After that, each module's capacity will be tested and classified into regenerable and unregenerable modules. Regenerable modules will be regenerated by repeating chargedischarged circulation. According to the regeneration manufacturer, regenerated $\mathrm{NiMH}$ will share $80 \% \sim 85 \%$ of a new NiMH batteries' capacity. Based on the interview result from the battery regeneration operator, the capacity for regenerated $\mathrm{NiMH}$ is set to be $80 \%$. Regenerated batteries will be transported to each dealer, while unregenerable modules will be sent to the recycling plant and are out of the research scope (Fig.2). 
Shuoyao Wang, Jeongsoo Yu: Life-Cycle Assessment on Nickel-Metal Hydride Battery in Hybrid Vehicles: Comparison between Regenerated and New Battery

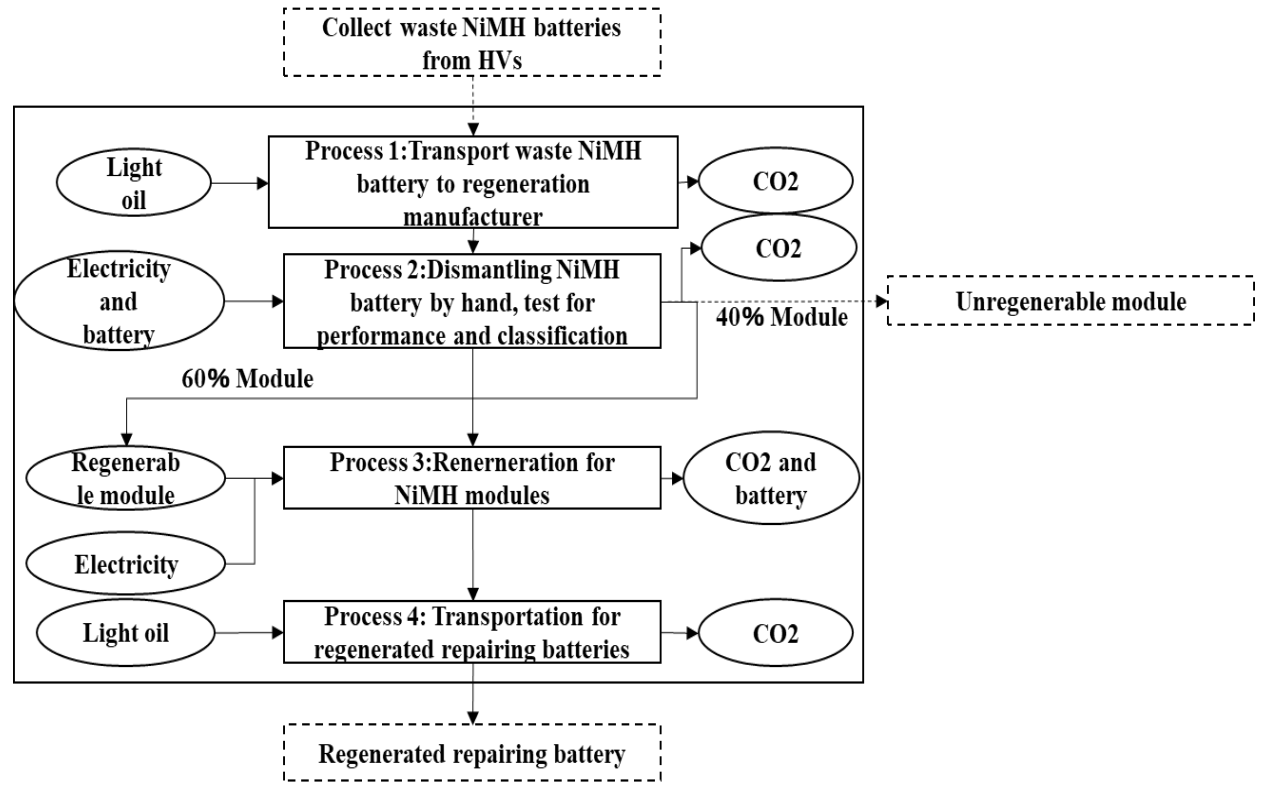

Fig. 2: Research scope of regenerated repairing NiMH batteries for $H V$ Figure 2 was created by the author

\section{Inventory Assessment of NiMH Battery}

In inventory assessment, resources and energy consumption during $\mathrm{NiMH}$ battery (both new and regenerated) production to shipment processes should be grasped first. And these consumptions will be multiplied by their $\mathrm{CO} 2$ emission intensities, the result will be rounded off to integral number.

\subsection{Inventory Assessment of regenerated batteries}

For regenerated batteries, the data for all process is gathered from interview research on a battery regeneration company in Japan. According to battery regeneration traders, used $\mathrm{NiMH}$ batteries are mainly collected through dual routes: recycling subcontractors (86\%, 50 per month) and their own company (14\%, 8 per month). When these batteries were collected from recycling subcontractors, they were estimated to be collected from Kyushu district $(1,138 \mathrm{~km}, 10 \mathrm{NiMH}$ batteries) and Kansai district $(550 \mathrm{~km}, 40 \mathrm{NiMH}$ batteries). The transportation of recycled battery is done through a courier and is considered to be one-way transportation. On the other hand, when the batteries were collected from their own company, it is dismantled from End-of-Life HV, but the amount is comparatively small (14\%). Therefore, only the $\mathrm{CO} 2$ emission during battery transportation from recycling subcontractors is calculated. $\mathrm{CO} 2$ emission during transportation is calculated by the ton-kilometer method 
as written in Eq. (1) (Ministry of Land, Infrastructure, Transport and Tourism of Japan 2016a), where $\mathrm{E}_{\mathrm{CO} 2}$ means $\mathrm{CO}_{2}$ emission, $\mathrm{D}_{\mathrm{t}-\mathrm{k}}$ is ton-kilo of transportation, $\mathrm{I}_{\mathrm{f}}$ is transport vehicles fuel efficacy, Cal. is calorific value of the fuel and $\mathrm{I}_{\mathrm{co} 2}$ is $\mathrm{CO} 2$ emission intensity of the fuel.

$$
E_{\mathrm{CO} 2}=D_{t-k} * I_{f}^{*} 1 / 100 O * \text { Cal. }{ }^{*} I_{\mathrm{co} 2} * 44 / 12 \text { (1) }
$$

The assumption that when the batteries are transported from Kyushu district, they were transported by a 4-ton truck, and the load factor is around 58\%. When the batteries were collected from Kansai district, they were transported by a 2-ton truck, and the load factor is about $80 \%$. Thus, the $\mathrm{CO} 2$ emission for batteries from Kyushu is $150 \mathrm{~kg}$ in total, and $15 \mathrm{~kg}$ for each (10 batteries at one time) and is $350 \mathrm{~kg}$ for batteries from Kansai and $8.8 \mathrm{~kg}$ for each (40 batteries at one time). That is to say, to collect one used battery from recycling subcontractors, 10kg $\mathrm{CO} 2$ will be discharged on the average.

However, as battery regeneration manufacturers claim, only $60 \%$ of the module in one used $\mathrm{NiMH}$ batteries can be regenerated on the average. Consequently, 1.7 wasted batteries will be needed to make a regenerated battery. Based on this assumption, to transport one regenerable battery to the plant will cause about $17 \mathrm{~kg} \mathrm{CO} 2$ emission.

As to exam used battery function, recycled batteries will be dismantled into modules first, and the remaining capacity of each module will be evaluated. After that, these modules will be classified as "regenerable" and "non-regenerable" module, based on the difference of capacity of each battery module and the discharge time. On average, it will cost $2 \mathrm{kWh}$ electricity to examine one module as battery regeneration operators claimed. As mentioned before, since it will cost 1.7 used battery to make a regenerated battery, $3.4 \mathrm{kWh}$ electricity will be used during this process. $\mathrm{CO} 2$ emission in this process is calculated by Eq. (2) (Federation of Electric Power Companies of Japan 2017), where $\mathrm{E}_{\mathrm{CO} 2}$ means $\mathrm{CO}_{2}$ emission, $\mathrm{E}_{\mathrm{b}}$ stands for the energy consumption for regenerate one battery, and $I_{e}$ means the intensity for energy generation, which is $0.531 \mathrm{~kg}-$ $\mathrm{CO} 2 / \mathrm{kWh}$ in Japan.

$$
E_{\mathrm{CO} 2}=E_{b}{ }^{*} I_{e}(2)
$$

The result shows that the dismantlement, examination and classification process will discharge about $2 \mathrm{~kg} \mathrm{CO} 2$. As for $\mathrm{NiMH}$ battery regeneration process, to regenerate one $\mathrm{NiMH}$ battery, it will cost 10kWh electricity, and no other components such as BMS (Battery Management System) or cooper connector are needed. Therefore, the $\mathrm{CO} 2$ emission is mainly from electricity consumption (calculated by Eq. 2, and the result is $5 \mathrm{~kg}$ - CO2/battery). Also, regenerated batteries' capacity is assumed to be $80 \%$ compared to a new NiMH battery. After waste batteries are 
Shuoyao Wang, Jeongsoo Yu: Life-Cycle Assessment on Nickel-Metal Hydride Battery in Hybrid Vehicles: Comparison between Regenerated and New Battery

regenerated, they will be shipped to dealers around the world. On the average, 30 regenerated batteries will be shipped by couriers. However, a specific destination is not clear. In this research, the distance between shipping destination and regeneration plant is assumed to be around $200 \mathrm{~km}$ and is transported by a 2-ton truck with 60\% load rate (Ministry of Land, Infrastructure, Transport and Tourism of Japan 2016a). The CO2 emission in this process is calculated by Eq. 1 and is $4 \mathrm{~kg}$ for each regenerated battery.

Based on previous inventory analysis, to make one regenerated $\mathrm{NiMH}$, about $28 \mathrm{~kg} \mathrm{CO} 2$ will be produced. When looking at each process, process 1 occupies the most emission (61\%), process 2 occupies the least (7\%) of the overall emission.

\subsection{Inventory Assessment of New NiMH Batteries}

As mentioned before, NiMH battery consists of battery modules and battery case. Battery modules include the positive electrode, separator, negative electrode, electrolyte and battery jar (Oshitani 2008; Nittetsu 2017). The positive electrode is mainly made of nickel hydroxide while the negative electrode is made of $\mathrm{AB}_{5}$ type hydrogen-absorbing alloy (Ikoma and Fukuda 1997). The separator is made of PP, the electrolyte is made of calcium hydroxide, and the battery jar is made of steel. Since detailed materials and constitution of NiMH are not published by vehicle or battery makers, these data are mainly collected from previous studies and were calculated by weight ratio. The constitution and weight of each material is listed in table 1, data No.1 and No.4 tend to observe less nickel hydroxide in the NiMH. The reason could be that the nickel hydroxide is calculated as metal in these studies. Data No.5 calculated the positive and negative electrode separately, and the overall ratio surpassed $100 \%$ already. Also, when comparing data No.3 and No.2, the latter is more detailed. Therefore, the constitution and material of HVs' new NiMH are evaluated based on the data from the Japanese Ministry of Economy, Trade and Industry. On the other hand, the material and weight of battery case are based on the result of interview research on battery regeneration manufacturing. The material and weight of battery modules and case are listed below.

Table 1: Information of material for NiMH in previous research.

\begin{tabular}{|c|c|c|c|c|c|c|c|c|c|c|c|c|c|c|c|c|c|c|}
\hline \multicolumn{19}{|c|}{ Material and consititution of NiMH battery in percent } \\
\hline & Hydrogen abourbing alloy & $\mathrm{Ni}(\mathrm{OH}) 2$ & $\mathrm{Ni}$ & Porous nicke & $\mathrm{Co}(\mathrm{OH})_{2}$ & $\mathrm{Fe}$ & $\mathrm{Zn} 0$ & $\mathrm{Cu}$ & Aluminium alloy & $\mathrm{KOH}$ & PTFE & PP & ABS & Others & Total & Object & Publish year & Researcher \\
\hline N0.1 & 5 & & 29. & & 1.7 & 43.5 & - & - & - & 9 & 1 & 5 & - & 5.6 & 100 & - & 2006 & Kaziyama et al. \\
\hline N0.2 & 31.7 & 20 & 2.2 & 4.9 & 2.2 & 8.8 & 1.1 & 0.8 & 3.7 & 13.2 & 1 & 9.9 & 0.4 & 0.1 & 100 & - & 2008 & $\begin{array}{c}\text { Ministry of } \\
\text { Economy, Trade } \\
\text { and Industry of } \\
\text { Japan }\end{array}$ \\
\hline N0.3 & 31.7 & 23.3 & 1.6 & 4.9 & - & 9.9 & - & - & 3.7 & 13.2 & 1 & 2.1 & 8.1 & 0.5 & 100 & Modules & 2008 & Sakai \\
\hline $\mathrm{N} 0.4$ & 7 & & 23 & & 4 & 36 & - & - & - & 9 & 1 & & 18 & 2 & 100 & - & 2010 & Nickel Institute \\
\hline N0.5 & 28 & & & 23 & & 21 & $\begin{array}{ll}- \\
-\end{array}$ & - & $\begin{array}{llll}- & \\
-\end{array}$ & 13 & - & 3 & 13 & - & 101 & Modules & 2013 & Larsson et al. \\
\hline
\end{tabular}


(Kaziyama et al. 2006; Ministry of Economy, Trade and Industry of Japan 2008; Sakai 2008, Nickel Institute 2010; Larsson et al. 2013)

\begin{tabular}{|c|c|c|}
\hline Modules & Material & Weight (kg) \\
\hline Alloy for negative electrode & Hydrogen absorbing alloy & 9.23 \\
\hline Active material for positive electrode & $\mathrm{Ni}(\mathrm{OH}) 2$ & 5.81 \\
\hline Active material for positive electrode & $\mathrm{Co}(\mathrm{OH}) 2$ & 0.64 \\
\hline Active material for positive electrode & $\mathrm{ZnO}$ & 0.33 \\
\hline collector for negative electrode & Plate Fe-Ni & 1.55 \\
\hline Plate for negative electrode & Plate nickel $(0.15 \mathrm{~mm})$ & 0.25 \\
\hline collector for positive electrode & Porous nickel & 1.44 \\
\hline Plate for positive electrode & Plate nickel $(0.15 \mathrm{~mm})$ & 0.24 \\
\hline binding materia for negative electrode & Coating PTFE & 0.28 \\
\hline $\begin{array}{c}\text { Pole } \\
\end{array}$ & Plate Fe-Ni & 0.92 \\
\hline Battery erector & Plate Cu-Ni & 0.23 \\
\hline Bolt & Plate Fe-Ni & 0.23 \\
\hline Electrolyte & KOH & 3.84 \\
\hline Safety valve (PP) & PP & 2.31 \\
\hline Separator(PP) & PP & 0.57 \\
\hline Battery module cover (ABS) & ABS & 0.11 \\
\hline Back-up plate & Iron & 0.06 \\
\hline Reinforcing materials & Aluminium alloy & 1.08 \\
\hline Sum & & 29.12 \\
\hline Attchment: Battery case & Material & Weight (kg) \\
\hline Case and bar to keep modules & Iron and plastic & 1.6 \\
\hline Top cover of battery case & Iron & 1.75 \\
\hline Side cover of battery case & Iron & 0.65 \\
\hline Bottom of battery case & Iron and harness & 4.5 \\
\hline Fan & Plastic & 0.7 \\
\hline Others（Plastic and cable） & Plastic and cooper & 0.75 \\
\hline Sum & & 9.95 \\
\hline
\end{tabular}

Table 2 was created by the author

As shown in table $2,76 \%$ of $\mathrm{NiMH}$ module $(22.01 \mathrm{~kg})$ is made from the metal resource. Specifically, hydrogen-absorbing alloy and nickel hydroxide occupied $52 \%$ of the NiMH module. Plastic is $11 \%$, while electrolyte is about $13 \%$. On the other hand, the material for battery case is mainly iron, despite some small quantity of other materials. Since more detailed information is unavailable, material "iron and plastic" and "iron harness" are all calculated as iron, and "plastic and cooper" is classified as plastic. Also, all the types of plastic are considered as PP.

Part of the $\mathrm{CO} 2$ emission intensity for the material is not published yet, therefore, these materials are replaced by other materials. And the $\mathrm{CO} 2$ emission intensity is collected from previous studies, refining plants and, Life Cycle Assessment Society of Japan (JLCA). Replaced materials are shown in table 3 , and $\mathrm{CO}_{2}$ emission for producing each material is shown in Fig. 3. 
Shuoyao Wang, Jeongsoo Yu: Life-Cycle Assessment on Nickel-Metal Hydride Battery in Hybrid Vehicles: Comparison between Regenerated and New Battery

Table 3: Material replacement for NiMH battery

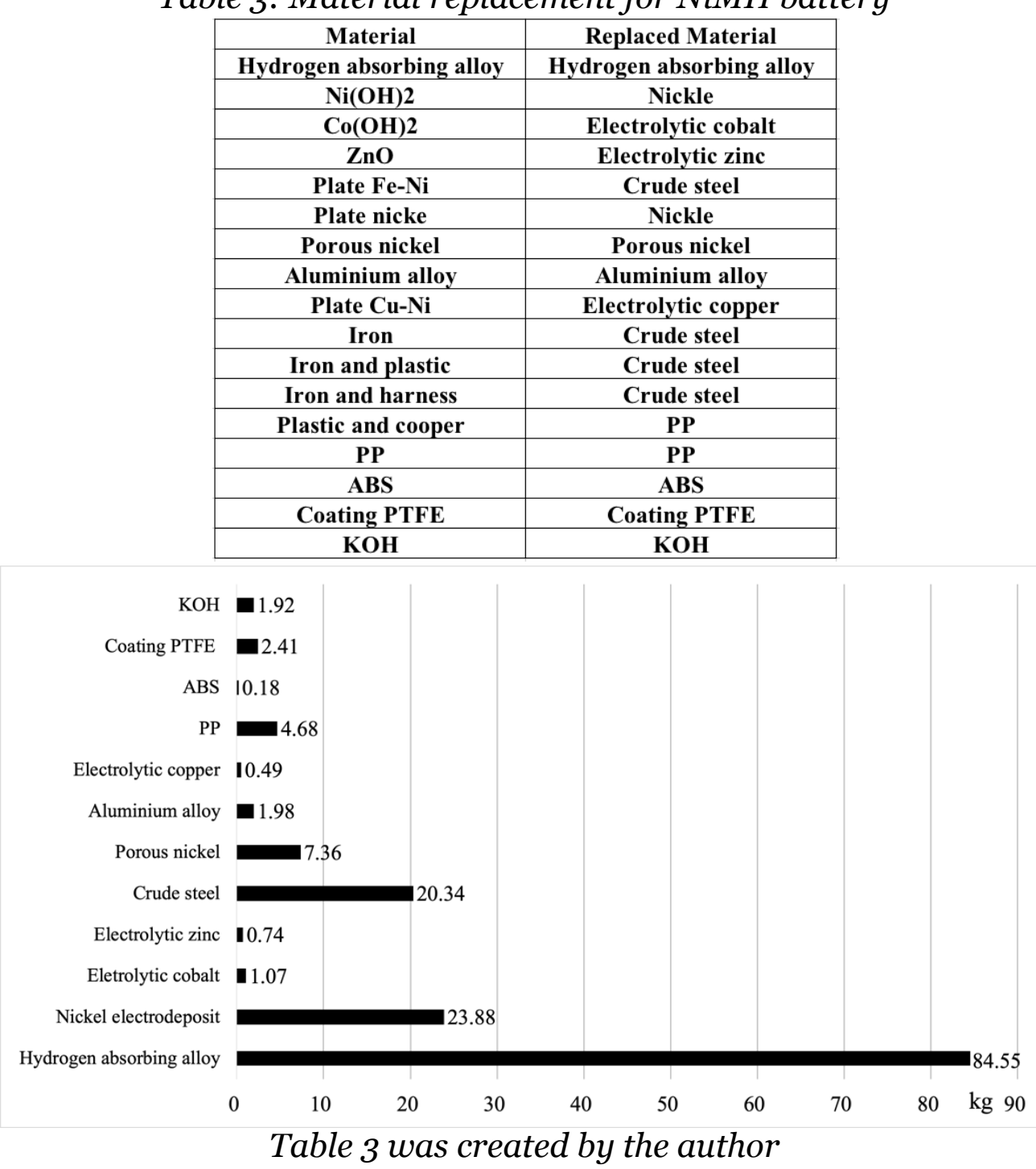

Fig 3: $\mathrm{CO}_{2}$ emission during raw material production process

(LCI data for nickel electrodeposit referenced from Onishi and Miyazawa 2014; LCI data for electrolytic cobalt referenced from Japanese Ministry of the Environment 2001; LCI data for electrolytic zinc referenced from Mitsui Mining \& Smelting 2012; LCI data for crude steel referenced from Japan Iron and Steel Federation 2013; LCI data for electrolytic copper referenced from Narita et al. 2001; LCI data for aluminum alloy, PP and ABS referenced from Life Cycle Assessment Society of Japan; LCI data for hydrogen absorbing alloy, porous nickel, coating PTFE and $\mathrm{KOH}$ referenced from Sakai 2008)

The result shows that during the material production process, about 150kg CO2 are being discharged. Among all the materials, production 
of nickel hydroxide comes with most $\mathrm{CO} 2$ emission (52\%), and production of nickel electrodeposit is the second (16\%), which means $\mathrm{CO} 2$ emission reduction during nickel hydroxide production process is important. This goal may be achieved by using alternative material.

In NiMH battery manufacturing process, battery materials are divided into cathode material, anode material, electrolyte, and battery cover (Sakai 2008) ${ }^{1}$. $\mathrm{CO} 2$ emission for transporting these materials from material plants to battery manufacture plant (Primeearth EV Energy, Omori Plant) are calculated. Cathode material is made by SUMITOMO Metal Mining (516km, 22\% of overall weight), anode material is made by CHUO DENKI KOGYO $(385 \mathrm{~km}, 29 \%$ of overall weight), electrolyte is made by AGC HUB (354km, 11\% of overall weight) (Ministry of Finance 2016) and battery cover is made by Pacific Industrial (715km, 38\% of overall weight). Battery manufacture plant will receive 10 tons of material for one time. After the reception, trucks will return to their separate plant. $\mathrm{CO} 2$ emission during raw material transportation is calculated by their weight ratio and Eq. (1) mentioned before.

As Fig.4 shows, to transport 10 tons of battery raw material, 2,377 tons of $\mathrm{CO}_{2}$ will be discharged. Since 10 tons of raw material can make 256 batteries, $\mathrm{CO}_{2}$ emission during raw material transportation process for one battery is $9 \mathrm{~kg}$. The delivered raw material will be made into batteries' components first, and then, components will be assembled into modules, and finally NiMH batteries. In this research, the assemble and production process is considered to be the same (Rantik 1999: 17). This process is considered to cause about $30 \mathrm{~kg} \mathrm{CO} 2$ emission. Most new NiMH batteries are used in new HVs rather than a secondhand HV, which means that new repairing NiMH batteries made for secondhand vehicles are little. Therefore, the shipment process of new repairing batteries is considered to be the same as normal new batteries, and the shipment for one new repairing battery will cause about $4 \mathrm{~kg}$ of $\mathrm{CO}_{2}$ emission. Therefore, $\mathrm{CO}_{2}$ emission from battery production to shipment is around $193 \mathrm{~kg}$, this number is almost the same with the assumption made by the previous study (Wu, 2017), and the raw material production process occupies about $78 \%$ of that emission.

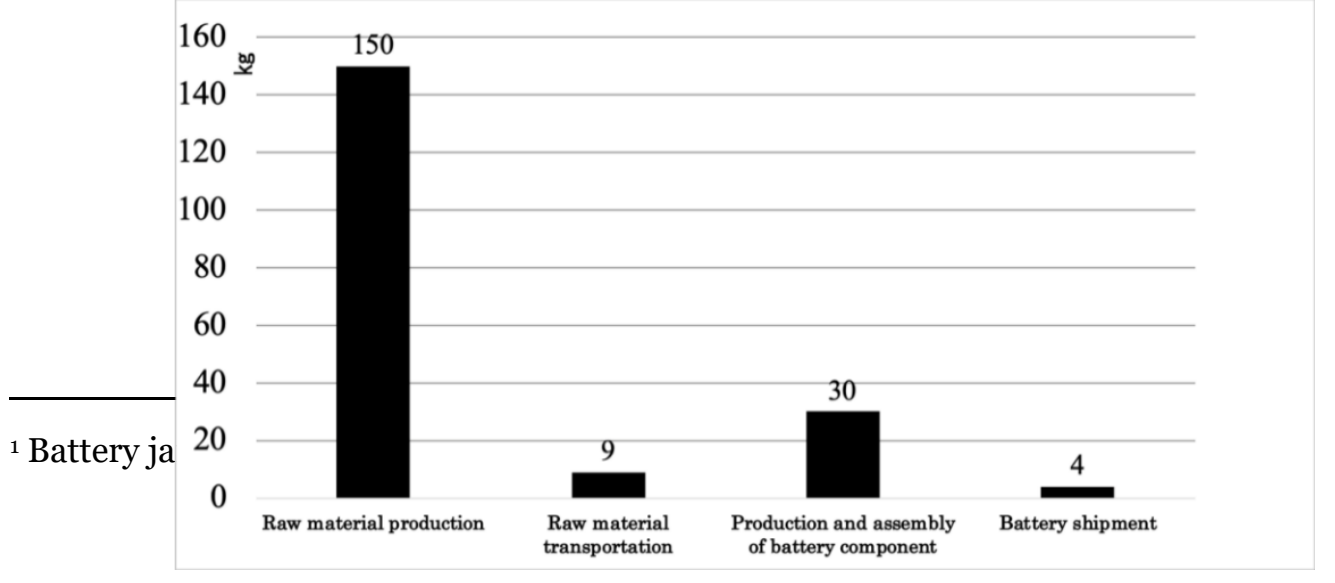


Shuoyao Wang, Jeongsoo Yu: Life-Cycle Assessment on Nickel-Metal

Hydride Battery in Hybrid Vehicles: Comparison between Regenerated and New Battery

Fig 4: $\mathrm{CO}_{2}$ emission during new repairing battery production process to shipment process

Figure 4 was created by the author

\section{Life-Cycle Inventory Assessment: Results}

For the result of inventory assessment for a new NiMH battery, the production to shipment process will discharge 193kg of CO2 and only $28 \mathrm{~kg}$ for a regenerated NiMH battery. That is to say, by using regenerated repairing batteries, about $165 \mathrm{~kg} \mathrm{CO} 2$ emission can be saved (Fig. 5). Since the transportation process occupies $75 \% \mathrm{CO} 2$ emission for a regenerated $\mathrm{NiMH}$ battery, $\mathrm{CO} 2$ reduction by using a low-emission vehicle or improving recycling rate is expected. In comparison, for a new repairing battery, since most $\mathrm{CO}_{2}$ (78\%) is discharged from raw material production process, usage of recycled material or materials with lower $\mathrm{CO} 2$ intensity are recommended.

Next, the environmental impact of a new and a regenerated $\mathrm{NiMH}$ battery will be compared with resource efficiency concept written in Eq. (3) (Matsuto et al. 2007). In Eq. (3). E means resource efficiency, and V is the value of one product, which is calculated by multiplying the batteries' performance against the lifespan in this research. $I_{r}$ stands for the resource input and refers to $\mathrm{CO} 2$ emission reduction effect during all process.

$$
E_{r=V / I}(3)
$$

In Eq. (3), the result is called "Factor X", as the factor X becomes larger, the product will be considered to be more environmentally friendly. Generally, in advanced countries, this number is expected to be larger than four in the present time and over 10 in the middle of the 21st century.

As the basic scenario for this research, the performance of the regenerated repairing battery equals to $80 \%$ of new repairing battery, and the lifespan is the same. Resource inputs for regenerated repairing battery are only $15 \%$ compared to new repairing battery. Consequently, the resource efficiency for regenerated repairing battery is $0.8 * 1 / 0.15=5.3$ and is larger than four (4). On the other hand, to promote new repairing batteries' resource efficiency to the recommended level (factor X over 4), overall CO2 emission should be under 140kg. 


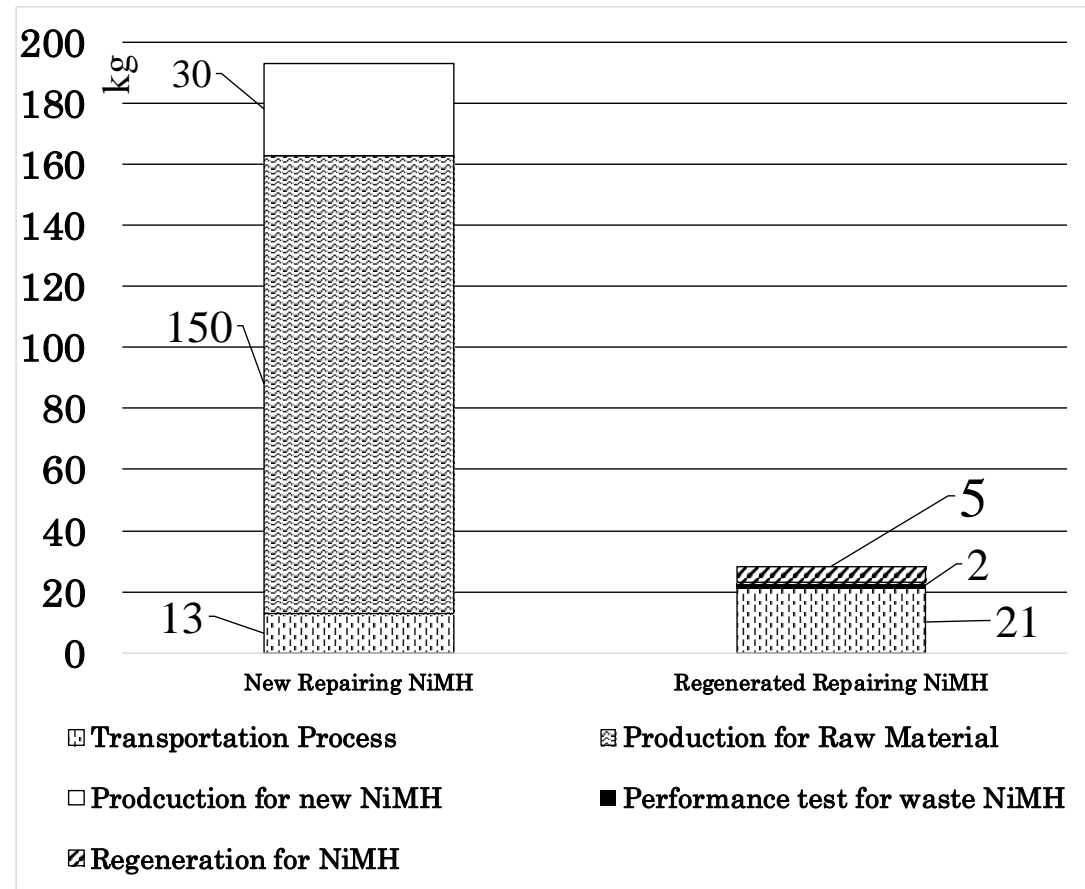

Fig 5: $\mathrm{CO}_{2}$ emission in each process Figure 5 was created by the author

\section{The Reuse of NiMH Battery and Resource Savings}

In this section, resource savings and waste reduction effect of regenerating a waste NiMH battery will be analyzed. First, as for resource savings, metal resources (including hydrogen-absorbing alloy, nickel electrodeposit, electrolytic cobalt, crude steel, aluminum alloy and electrolytic copper) which have been largely used in NiMH will be the main research object 2 .

As Fig. 6 shows, by making a repairing battery out of 1.7 waste battery rather than raw materials, 3okg metal resources will be saved. Among all these metals, nickel is about $7.7 \mathrm{~kg}$, cobalt is $0.6 \mathrm{~kg}$, these metals can satisfy $55 \%$ nickel and cobalt demand for one HV (Yano et al. 2016). On the other hand, as for the waste reduction effect of regenerate one NiMH battery, when assuming reuse rate for battery case is the same to NiMH battery modules $(60 \%)^{3}, 23 \mathrm{~kg}$ waste will be reduced.

\footnotetext{
2 PP, ABS and PTFE are all classified as "Plastic"

3 on average, to manufacture one regenerated NiMH, 1.7 waste NiMH will be used. Therefore, the reuse rate for battery case is $1 / 1.7$ and is around $60 \%$
} 
Shuoyao Wang, Jeongsoo Yu: Life-Cycle Assessment on Nickel-Metal Hydride Battery in Hybrid Vehicles: Comparison between Regenerated and New Battery

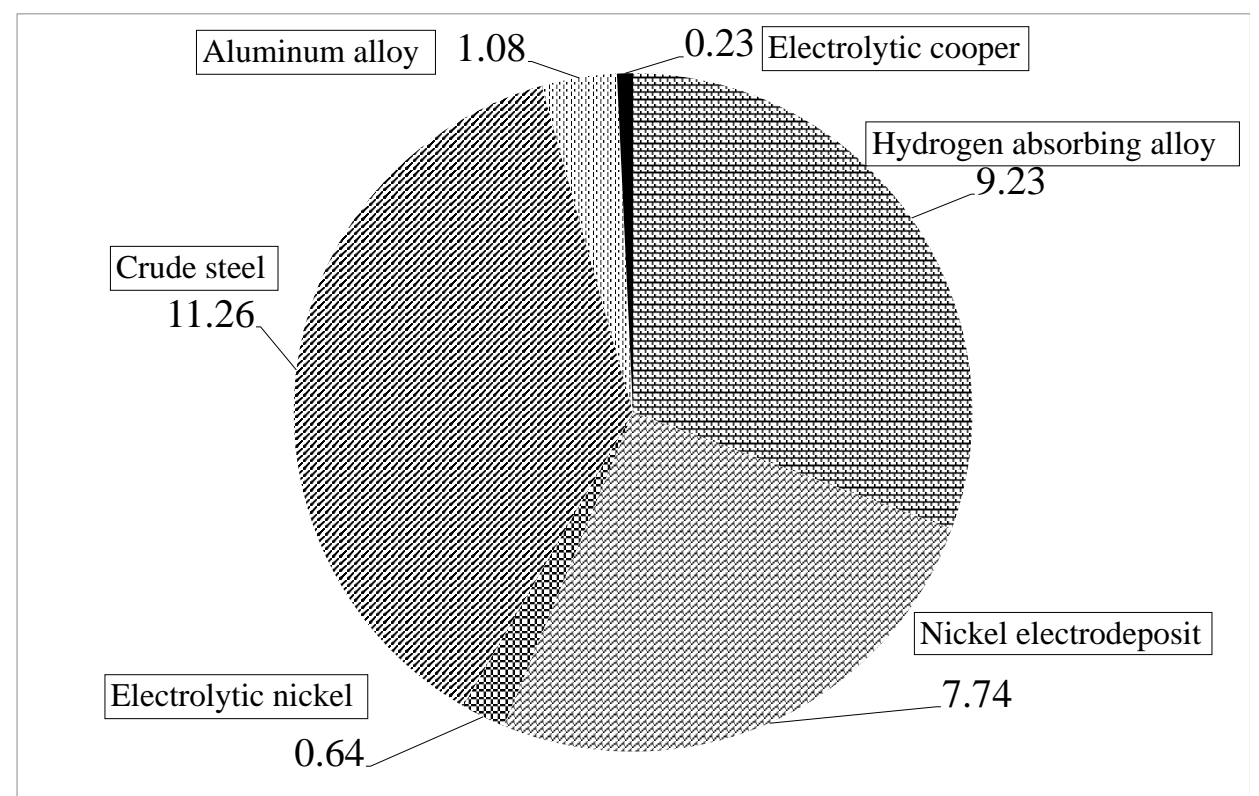

Fig 6: Metal resource consumption during new NiMH battery production Figure 6 was created by the author

\section{Comparison in the Usage of HV: Focusing on $\mathrm{CO} 2$ Emission}

In this research, repairing $\mathrm{NiMH}$ battery is assumed to be used in a 5-year old HVs, which is also the warranty time offered by the vehicle maker. In this section, ordinary gasoline vehicle 4 , HV without a repairing battery, HV with a regenerated repairing battery 5 and $\mathrm{HV}$ with a new repairing battery will be compared based on their $\mathrm{CO} 2$ emission from years 6-10. Based on JC-o8 mode (Japan Automobile Federation 2013) ${ }^{6}$, fuel consumption for a $\mathrm{HV}$ is around $32.6 \mathrm{~km} / \mathrm{L}$ (E-fuel) and $16.4 \mathrm{~km} / \mathrm{L}$ for an ordinary gasoline vehicle according to Toyota. This means that by using NiMH battery with $100 \%$ capacity, vehicles' performance will be upgraded for 0.99 times. On the other hand, time-related deterioration for $\mathrm{NiMH}$ battery and engine is needed to be known.

In fact, NiMH batteries' capacity will degrade for $50 \%$ after being charged for 1800 times (Ikeya et al. 2002), and vehicle use frequency in Japan is five days per week in 2015 (Japan Automobile Manufacturers

\footnotetext{
4 Axio of TOYOTA, $2 \mathrm{WD}, 1.8 \mathrm{~L}$, and the weight is assumed to be around $1,230 \mathrm{~kg}$ to $1,505 \mathrm{~kg}$ ${ }^{5} 3$ rd generation of Prius, $2 \mathrm{WD}, 1.8 \mathrm{~L}$ with the motor, the weight is assumed to be $1,310 \mathrm{~kg}$ ${ }^{6} \mathrm{JC}-08$ mode means the vehicle emission will be tested when the vehicle engine is started in low temperature and will consider speed variation
} 
Association 2016), and 260 days per year. If each time the vehicle was being used, the NiMH battery will be fully charged for one time, it will cost 7 years before the battery capacity degrades to $50 \%$ (degradation rate of $7 \%$ per year). As for the degradation rate for the engine, it is $1.6 \%$ per year (WU 2015).

According to these results, when vehicles' weight is all the same, fuel consumption for vehicles without a repairing battery will be $25.6 \mathrm{~km} / \mathrm{L}$ from the 6th year and is $28.8 \mathrm{~km} / \mathrm{L}$ for vehicles with a regenerated repairing battery, $15.09 \mathrm{~km} / \mathrm{L}$ for an ordinary gasoline vehicle. $\mathrm{CO}_{2}$ emission during vehicles' running process was calculated when assuming the annual running distance is $8,085 \mathrm{~km}$ (Ministry of Land, Infrastructure, Transport and Tourism 2016b; Automobile Inspection \& Registration Information Association 2017). $\mathrm{CO} 2$ emission during vehicles' running stage is calculated by Eq. (4) (Ministry of the Environment Government of Japan 2012). In Eq. (4), $\mathrm{E}_{\mathrm{co} 2}$ is $\mathrm{CO}_{2}$ emission $(\mathrm{kg}), \mathrm{C}_{\mathrm{g}}$ is gasoline consumption (L), $\mathrm{I}_{\mathrm{co} 2}$ means the $\mathrm{CO}_{2}$ emission intensity during fuel combustion in Japan and is around $2.32 \mathrm{~kg}-\mathrm{CO}_{2} / \mathrm{L}$.

$$
E_{\mathrm{co} 2}=C_{g}{ }^{*} I_{\mathrm{co} 2} \text { (4) }
$$

Moreover, when the voltage for NiMH battery is extremely low, the engine will burn some fuel to charge the battery. However, since it is hard to know the frequency or the fuel consumption during this process, NiMH battery is assumed to be charged only by recovered energy from braking process. Transition of fuel consumption of each kind of vehicle from year 6-10 is also shown in Fig7.

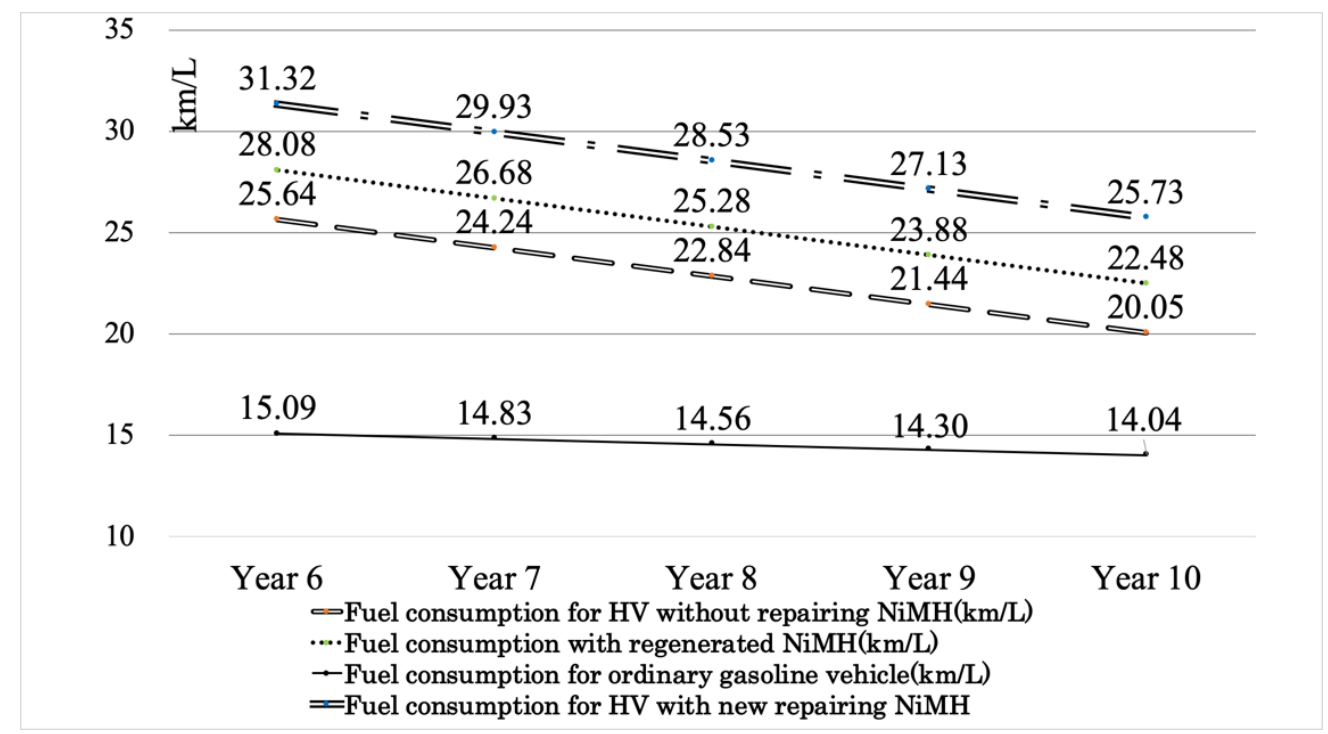

Fig 7: Fuel consumption for vehicles and its transition

Figure 7 was created by the author 
As for $\mathrm{CO} 2$ emission during the vehicles' running process as shown in Fig. 8, in five years, ordinary gasoline vehicle will produce $6,444 \mathrm{~kg} \mathrm{CO} 2$ during the running process and is about $2,114 \mathrm{~kg} \sim 2,754 \mathrm{~kg}$ more than HVs, even when considering the $\mathrm{CO} 2$ emission during the battery manufacturing process. On the other hand, HV without a repairing battery will produce 4,330kg $\mathrm{CO} 2$, $\mathrm{HV}$ with a regenerated repairing battery is $376 \mathrm{~kg}$ less than this $(3,954 \mathrm{~kg}$ CO2). This means that even if the NiMH battery is a regenerated one, vehicle emission during the running process can still be reduced. Also, $\mathrm{CO} 2$ emission for $\mathrm{HV}$ with a regenerated repairing battery is only 264kg larger than $\mathrm{HV}$ with a new repairing battery. This result is enlightening for not only advanced countries but also developing countries such as Mongolia. It is because Mongolia is importing plenty of secondhand vehicles from Japan and most of these secondhand vehicles have been used for over 15 years. Under this scenario, the NiMH battery in these vehicles may be unfunctional already. This means that unless old NiMH battery in exported vehicles is replaced, these vehicles should not be considered as an "eco-friendly HV". For these countries, replacing unfunctional NiMH battery with a regenerated one could be an environmental countermeasure.

Japan owns NiMH battery regeneration technology but it failed to collect waste NiMH battery. One of the reasons is most NiMH batteries have been exported abroad along with old HV. Consequently, waste NiMH battery will emerge massively in secondhand HV exportation destination. However, since these countries have no reuse/recycling technology, waste $\mathrm{NiMH}$ battery will be thrown away and treated inappropriately. It is recommended that Japan, who owns most HV, should put more effort into collecting, reusing and recycling waste NiMH battery on an international scale.

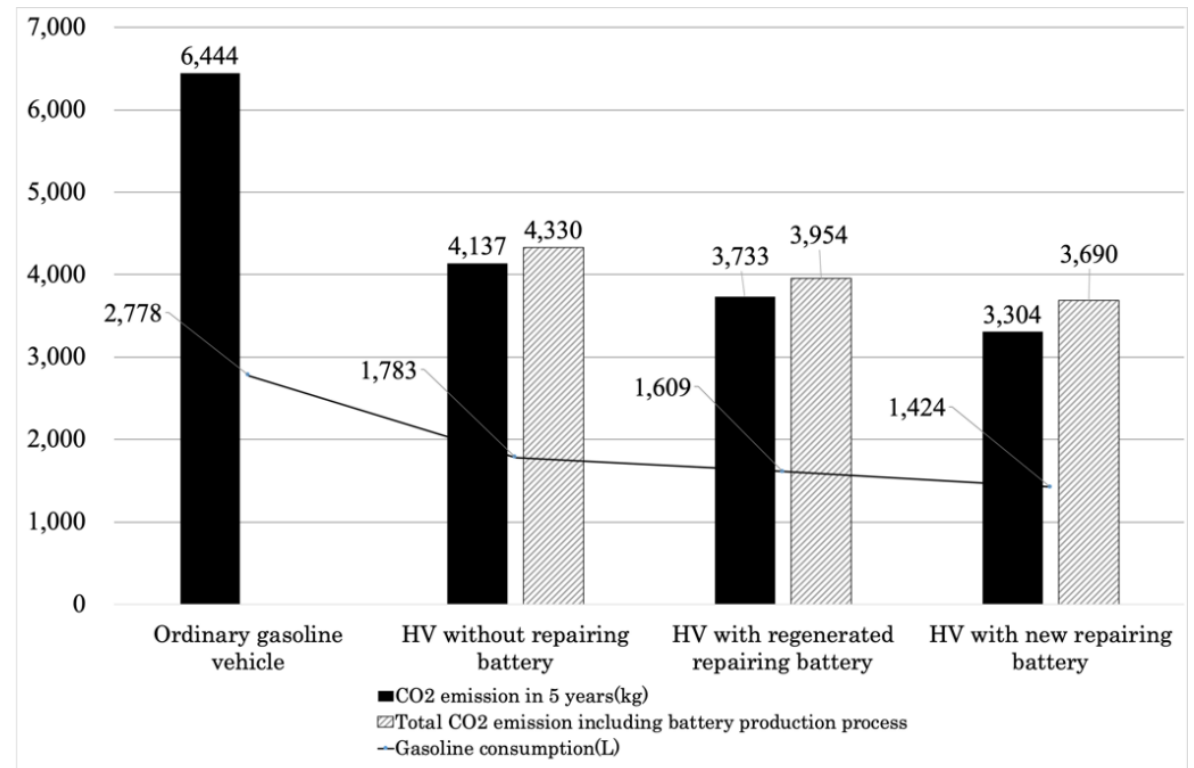


Fig 8: Vehicle Fuel Consumption and $\mathrm{CO}_{2}$ emission Figure 8 was created by the author

\section{Sensitivity Analysis of Recycling Rate on Resources Saving and Waste Occurrence}

In this section, Japanese end-of-life $\mathrm{HV}$ and NiMH battery recycling rate, as well as secondhand HV exportation situation in 2013, which have been published and with high dependability will be used for sensitivity analysis.

About 12,500 HV were sold in Japan in 2000 (TOYOTA 2017) and since the lifespan of a vehicle in Japan is around 13 years (Automobile Inspection \& Registration Information Association 2016), in 2013, there should be around 12,500 end-of-life HVs. However, there are only 6,000 end-of-life HV being dismantled in 2013 (Yano research institute 2015) which was half of the predicted number. The other half could be exported as secondhand vehicles. Moreover, only 3,000 waste NiMH batteries are collected in Japan at the same time (Japan Automobile Manufacturers Association 2018), which means that collection rate for used $\mathrm{NiMH}$ from domestic end-of-life $\mathrm{HV}$ in Japan is around 50\%. Uncollected NiMH batteries could be exported as secondhand parts. Moreover, in 2013, about 33,000 secondhand HV were exported (Yano research institute 2015). That is to say, nearly $19 \%(0.65 / 3.3)$ of exported HVs may be end-of-life HV.

In this section, two scenarios (all these old $\mathrm{NiMH}$ will be recycled or regenerated) and their sensitivity analysis will be discussed. As the premise for sensitivity analysis, the recycling rate for nickel and cobalt (the main target metal for recycling) is set to be $98.5 \%$ and $95.5 \%$

(Tenmaya 2008), respectively. Under this scenario, $7.6 \mathrm{~kg}$ nickel and $0.6 \mathrm{~kg}$ cobalt (total amount around $8 \mathrm{~kg}$ ) can be recycled from one waste $\mathrm{NiMH}$ battery. Resource-saving and waste reduction effect by $\mathrm{NiMH}$ reusing/recycling are shown in Fig. 9.

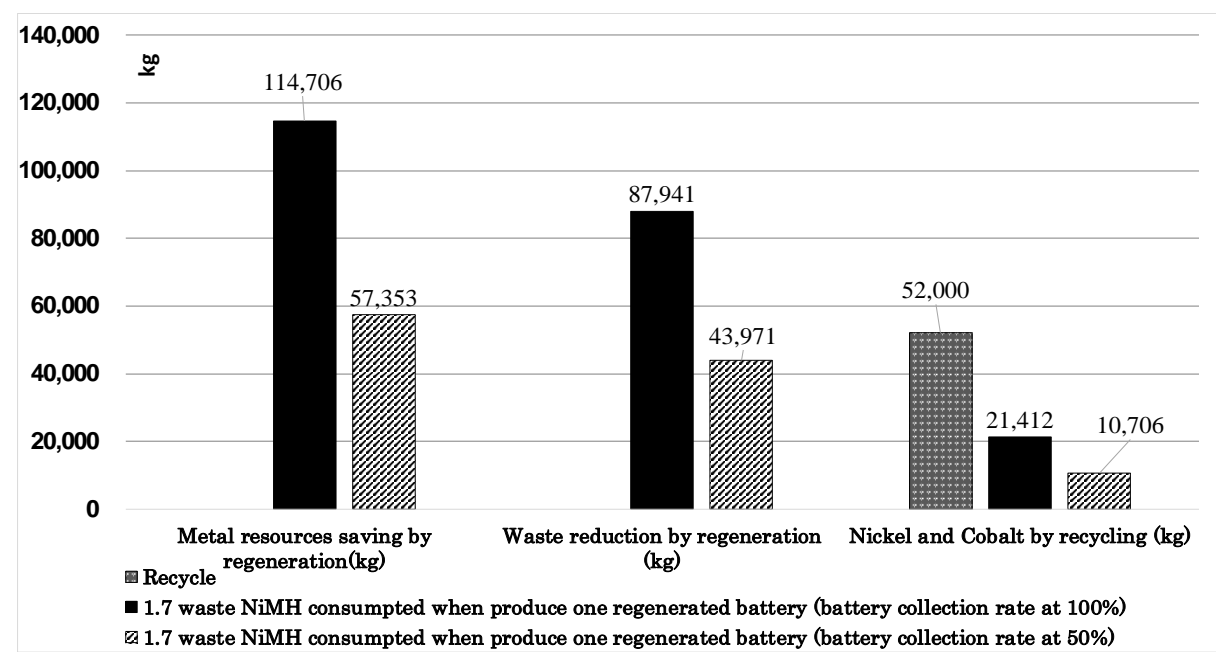

Fig 9: Result of sensitivity analysis for resource saving and waste 
Shuoyao Wang, Jeongsoo Yu: Life-Cycle Assessment on Nickel-Metal

Hydride Battery in Hybrid Vehicles: Comparison between Regenerated and New Battery

\section{reduction 7 \\ Figure 9 was created by the author}

If $19 \%$ of exported secondhand $\mathrm{HV}$ are end-of-life $\mathrm{HVs}$ and all the NiMH batteries in these HVs are recycled, 52,00okg nickel and cobalt will be recovered, and could be enough to make 3,444 HVs. On the other hand, by regenerating waste $\mathrm{NiMH}$ batteries, 43,971 87,941kg waste will be reduced, and $57,353 \mathrm{~kg} \sim 114,706 \mathrm{~kg}$ metal resources (nickel and cobalt range $16,059 \mathrm{~kg}$ to $32,118 \mathrm{~kg}$ ) will be saved. At the same time, from unregenerable batteries, $10,706 \mathrm{~kg} \sim 21,412 \mathrm{~kg}$ nickel and cobalt will be recycled. Therefore, when considering nickel and cobalt, 26,765kg $53,530 \mathrm{~kg}$ of these resources will be recycled. These resources are enough for making 1,773 3,545 HVs.

Based on the previous result, in 2013, about 52,00okg nickel and cobalt were not being used efficiently since they were exported abroad from Japan and treated inappropriately at exportation destination.

Secondhand HV will emerge at a faster speed as the sales of HVs grows in the future. To guarantee enough resource for HV production, it is important to collect waste $\mathrm{NiMH}$ battery from exported $\mathrm{HV}$ and reuse/recycle these batteries appropriately. Also, since the demand for regenerated $\mathrm{NiMH}$ could raise in the future, for advanced countries, proper treatment for exported $\mathrm{HV}$ and $\mathrm{NiMH}$ batteries should also be discussed. Since it is hard to install advanced recycling technology in developing countries within a short time, NiMH battery regeneration technology should be developed. Therefore, international scheme and cooperation on NiMH battery regeneration and reuse is essential.

\section{Summary}

Based on the result of this research, it is plain to see that regenerating and reusing waste NiMH battery will reduce massive $\mathrm{CO} 2$ emission and metal consumption.

Moreover, the result shows that using a regenerated NiMH battery, improves the environmental performance of an HV (6th year to 10th year). That is to say, other than reusing these NiMH batteries as stationary battery or recycle them directly, regenerating waste $\mathrm{NiMH}$ batteries and reusing them into a HV should also be considered as another option.

However, it is also true that the End-of-Life NiMH battery collected in Japan are mainly being recycled other than being reused in vehicles. That is because Japanese vehicle makers are aiming at selling new batteries

7 The nickel and cobalt from recycling is not included in the metal resource saving from remanufacture process 
instead of old batteries for profit and safety reasons. This manner of dealing with waste NiMH battery is clearly against the principle of waste hierarchy which advocates reuse before recycling. Even if the Japanese government and vehicle maker try to enhance waste NiMH battery recycling rate in Japan, collected NiMH battery remains small. Reason is that many developing countries are also starting to value the environment and are trying to improve air pollution by importing secondhand $\mathrm{HV}$ vehicles from Japan.

As the HV exportation number became bigger, the need for secondhand NiMH battery is also increasing, and thus, many of these batteries are being exported abroad. Japanese vehicle makers are also helpless to collect and recycle these NiMH batteries once they are exported. The reason is that it is hard to trace these batteries in developing countries, and even if Japanese vehicle makers are willing to bring these waste NiMH batteries back to Japan to recycle, they still face waste customs clearance as well as cost-performance problems.

Therefore, large quantity of waste NiMH battery will emerge in the secondhand HV recipient countries soon, where appropriate recycling technology and policy are generally lagging behind. It is fair to assume that metal resources may not be recycled with efficiency and under some circumstances, pollution problem may also emerge during the battery recycling process.

To avoid such situation, Japanese vehicle makers and the government may consider paying more to the vehicle dismantlers to ensure a higher recycling rate. Japanese battery remanufactures may offer more highquality remanufactured NiMH battery for secondhand HV importing countries. As these batteries will still emerge as End-of-Life battery in developing countries eventually, the possibility and validity for utilization of end-of-life NiMH in these countries should be considered in the future along with safeguards to ensure the environmental worthiness of these items. 
Shuoyao Wang, Jeongsoo Yu: Life-Cycle Assessment on Nickel-Metal Hydride Battery in Hybrid Vehicles: Comparison between Regenerated and New Battery

\section{Bibliography}

Automobile Inspection \& Registration Information Association of Japan. 2016. Li fe span transition for different kinds of vehicles. http://www.airia.or.jp/publi sh/file/r5c6pvoooooog7wb-att/r5c6pvoooooog7wq.pdf.

Automobile Inspection \& Registration Information Association. 2017. Vehicle own ership in 2016. https://www.airia.or.jp/publish/file/r5c6pvoooooog7wb-att/ r5c6pvoooooog7wq.pdf.

CHUO DENKI KOGYO CO., LTD, “Company history”, accessed October 12, 2017, http://www.chu-den.co.jp/company/history.html.

E-fuel consumption, "TOYOTA Prius", accessed October 15, 2017, https://e-nenpi .com/enenpi/cartype/10978.

Ebin B, Petranikova M, Ekberg C. 2018. Physical separation, mechanical enrichm ent and recycling-oriented characterization of spent NiMH batteries, Journal of Material Cycles and Waste Management, vol.20, no. 4, pp. 2018-2027. http s://doi.org/10.1007/s10163-018-0751-4.

Federation of Electric Power Companies of Japan. 2017. $\mathrm{CO}_{2}$ emission from electr icity generation, accessed September 18, 2017, https://www.fepc.or.jp/about _us/pr/pdf/kaiken_s_20170616.pdf.

Hu M, Ren F, Lei L, Lu X. 2013. Separation of cobalt from Ni (OH)(2) positive ma terials by a reduction and dissolution process in alkali solution, Separation an $d$ Purification Technology, vol. 120, pp. 198-205. https://doi.org/10.1016/j.se ppur.2013.09.037.

Ikoma M, Fukuda H. 1997. New technology for EV battery, Japan Science and Te chnology Agency, Miscellany, vol. 117, no. 1, p.24. https://doi.org/10.1541/ieej journal.117.22.

Ikeya T, Sawada N, Murakami J, Kobayashi K, Hattori M, Murotani N, Ujiie S, Ka jiyama K, Nasu H, Narisoko H, Tomaki Y, Adachi K, Mita Y, Ishihara K. 2002. Multi-step constant-current charging method for an electric vehicle nickel/met al hydride battery with high-energy efficiency and long cycle life, Journal of Po wer Resources, vol. 105, no. 1, p.10. https://doi.org/10.1016/So378-7753(01)o 0907-7.

Japan automobile federation. 2013. What is 10.5 mode and JCo8 mode, accessed September 20, 2017, http://qa.jaf.or.jp/mechanism/engine/o4.htm. 
Japan Automobile Manufacturers Association. 2016. Vehicle market trend for 20 15, accessed October 20, 2016, http://www.jama.or.jp/lib/invest_analysis/pdf /2015PassengerCars.pdf.

Japan Automobile Manufacturers Association. 2018. Situation of End-of-Life Nex t-Generation Vehicles' treatment and recycling, p. 5, https://www.meti.go.jp /shingikai/sankoshin/sangyo_gijutsu/haikibutsu_recycle/jidosha_wg/pdf/o4 6_03_02.pdf.

Japan Iron and Steel Federation. 2013. Effort on global warming countermeasu re, performance reporting on low-carbon society implementation plan, acces sed June 18, 2017, https://www.meti.go.jp/shingikai/sankoshin/sangyo_gijut su/chikyu_kankyo/tekko_wg/pdf/oo1_04_01.pdf.

Japanese Ministry of the Environment. 2001. Research for predicting the effect $o$ f material technology conversion on global environment prevention, accessed October 1, 2017, https://www.env.go.jp/earth/kenkyuhi/report/pdf/o3_1_2. pdf.

Kaziyama K, Okajima K, Uchiyama Y. 2006. Improvement effect evaluation by LC A on energy and environment by leveling battery electrical load, the Institute $o$ f Life Cycle Assessment, Japan, Vol.2, no. 4, pp. 379-385. https://doi.org/10.3 370/lca.2.379.

Korkmaz K, Alemrajabi M, Rasmuson A, Forsberg K. 2018. Sustainable Hydrom etallurgical Recovery of Valuable Elements from Spent Nickel-Metal Hydride HEV Batteries, Metals, no.8, pp.1-17. DOI: 10.3390/met8121062.

Larsson K, Ekberg C, Ødegaard-Jensen A. 2013. Dissolution and characterization of HEV NiMH batteries, Waste Management, vol. 33, no. 3, pp.689-698. https ://doi.org/10.1016/j.wasman.2012.06.001.

Life Cycle Assessment Society of Japan, "LCA data base", accessed October 20, 2 017, http://lca-forum.org/.

Matsuto T, Kakuta Y, Ishizaka K. 2007. Basic knowledge of evaluation technique f or Material- Cycle Society, Tanaka M (ed.), Life-Cycle Assessment, Gihodo sh uppan press, pp.103-128.

Mitsui Mining \& Smelting. 2012. Activities to improve the environment, accessed September 20, 2017. https://www.mitsui-kinzoku.co.jp/wp-content/uploads/ csr/2012/5.pdf.

Ministry of Economy, Trade and Industry. 2015. Situation for Next-Generation $V$ ehicle, accessed October 19, 2016, https://www.meti.go.jp/shingikai/sankoshi n/sangyo_gijutsu/haikibutsu_recycle/jidosha_wg/pdf/o37_05_oo.pdf.

Ministry of Economy, Trade and Industry of Japan. 2008. Research on material recycling of large rechargeable battery in Hokkaido, accessed September 12, 2017, https://www.meti.go.jp/policy/recycle/main/data/research/h19fy/1906 15-3_cjc/190615-3_d.pdf.

Ministry of Land, Infrastructure, Transport and Tourism, a. 2016. Guideline to ca lculate $\mathrm{CO}_{2}$ emission in transportation sector, accessed 15 June 2017, https:// www.greenpartnership.jp/co2brochure.pdf.

Ministry of Land, Infrastructure, Transport and Tourism, b. 2016. Fuel consumpt ion of Vehicle accessed December 12, 2017, https://www.gov-online.go.jp/data _room/publication/201304/details.html.

Ministry of the Environment Government of Japan. 2012. Guidebook for calculat ing Global warming prevention projects (first version), accessed August 20, 2 017, https://www.env.go.jp/earth/report/h24-05/full.pdf.

Ministry of Finance. 2016. Situation on Potassium hydroxide business, accessed October 23, 2017, https://www.mof.go.jp/about_mof/councils/customs_forei 
Shuoyao Wang, Jeongsoo Yu: Life-Cycle Assessment on Nickel-Metal Hydride Battery in Hybrid Vehicles: Comparison between Regenerated and New Battery

gn_exchange/sub-of_customs/proceedings_tokusyu/material/20160328/kan b20160328d.pdf.

Narita N, Sagisaka M, Inaba A. 2001. Life cycle inventory analyze on emission ele ctrolytic copper production system, Resources and Material, Vol.117, no.1, p.6 74. DOI: 10.2473/shigentosozai.117.49.

New Energy and Industrial Technology Development Organization. 2014. Techno logy for sludge reduction and metal recovery by using sulfide precipitation $m$ ethod, p. 21.

Nickel Institute. 2010. Green Scrap: Making New Stainless Steel, https://www.n ickelinstitute.org/NickelUseInSociety/MaterialsSelectionAndUse/Ni-Containi ngMaterialsProperties/ /media/Files/Magazine/Volume25/Vol25-01Jun201 $0 . \operatorname{ash} x \#$ Page $=16$.

Nittetsu technology. 2017. "Hydrogen absorbing alloy", accessed November 30, 2017, http://www.nsst.nssmc.com/tsushin/magazine/suisokyuuzou.pdf.

Ortego A, Valero A, Valero A, Restrepo E. 2018. Vehicles and Critical Raw Materi als: A Sustainability Assessment Using Thermodynamic Rarity, Journal of Ind ustrial Ecology, vol. 20, no. 5, pp. 1005-1015. https://doi.org/10.1111/jiec.1273 7.

Oshitani M. 2008. Development of large scale rechargeable batteries for vehicles, Sato N, Sakai T (ed.), Material technologies for NiMH battery in EV/HEV, C MC Pressed, p.38.

Pacific Industrial CO., Ltd, "Accelerate in making NiMH battery for $H V$ ", accesse d October 12, 2017, http://www.pacific-ind.co.jp/products/car/press/features /.

Primeearth EV Energy CO., Ltd, "Products introduction", accessed October 12, 20 17, https://www.peve.jp/en/product/.

Richa K, Babbitt CW, Nenadi NG, Gaustad G. 2017. Environmental trade-offs ac ross cascading lithium-ion battery life cycles, the International Journal of Life Cycle Assessment, Vol. 22, no. 1, pp. 66-81. doi: 10.1007/s11367-015-0942-3

Rantik M. 1999. Life Cycle Assessment of Five Batteries for Electric Vehicles unde r Different Charging Regimes, Chalmers University of Technology. http://see ds4green.net/sites/default/files/acv\%2obatterie\%20vehicule\%2oelectrique.p df.

Sakai T. 2008. Development of large scale rechargeable batteries for vehicles, Sat o N, Sakai T (ed.), Lifecycle design for NiMH battery, Development of vehicles 'rechargeable battery, CMC press, p.57.

Sumitomo Metal Mining CO., Ltd., "Introduction of plant base, Isouracho plant", accessed October 12, 2017, http://www.smm.co.jp/corp_info/domestic/isour a/kyoten.html.

Tenmaya Y. 2008. Substitute material and recycling of rare metal, Halada K, Nak amura T (ed.), Recycling of NiMH in HV, CMC Pressed, pp.315-325.

TOYOTA. 2017. "Sales of TOYOTA Hybrid Vehicle surpassed 10 million around $t$ he world", accessed December 20, 2017, https://newsroom.toyota.co.jp/jp/det ail/14940200.

WU B Offer GJ. 2017. Environmental Impact of Hybrid and Electric Vehicles. Harrison RM., Hester RE (Ed.) Environmental Impacts of Road Vehicles: Past, Present and Future. London: The Royal Society of Chemistry Press. pp.133-156. 
Wu C, Hyodo T. 2015. Determining factor for gasoline and light oil vehicles: base d on vehicle fuel consumption survey, Japan Society of Civil Engineers, vol.71, no.2, p. 49. https://doi.org/10.2208/jscejipm.71.44.

Yano Research Institute. 2015. Survey on Base of manufacturing technology (Cir culation of Metal resources from End-of-Life vehicles). https://www.meti.go.j p/meti_lib/report/2015fy/ooo560.pdf.

Yao Y, Farac N. F, Azimi G, Supercritical Fluid Extraction of Rare Earth Elements from Nickel Metal Hydride Battery, ACS Sustainable Chemistry \& Engineerin $g$, vol.6, no.1, pp. 1417-1426, https://doi.org/10.1021/acssuschemeng.7bo3803

Yano J, Xu G, Watanabe N, Sakai S. 2016. Resource potential of ELV and system evaluation on environmental burden, https://www.env.go.jp/policy/kenkyu/s uishin/kadai/syuryo_report/h26/pdf/3K123001.pdf. 